\title{
Evaluation of Various Brands of Moisture Meters in Gypsum and Wood Substrates at a Range of Moisture Contents
}

\author{
Abel Crean, CGC, EI, CIEC ${ }^{a^{*}}$ \\ a 561 BUILD 2787 East Oakland Park Blvd., Ft Lauderdale, Florida 33038, USA.
}

Received 15 August 2017; Accepted 21 September 2017

\begin{abstract}
Determining correct moisture content of wetted building materials and analysis of corresponding locations, orientations, and patterns is of imminent value to Forensic Engineers and building scientists. As many building damages relate to insurance claims and construction defect/ subrogation lawsuits, legal challenges to the accuracy of measured moisture content have arisen. The objective of this study was to independently establish the level of precision of common moisture meters used to quantify and measure moisture content in building components. The study tested four different brand moisture meters in gypsum and wood substrates at normal, high, and saturated moisture contents. The results were compared against laboratory obtained moisture content to assess the accuracy of each meter in the substrate and at which moisture content range.

The study wetted wood and gypsum specimens to moderate and saturated conditions and measured the resulting moisture content with the four different brands of meters. Control wood and gypsum specimens were not exposed to water and their moisture content was measured as is. All of the wood and gypsum specimens were subsequently sent to a laboratory and moisture content was calculated by the oven-dry method. The moisture content results measured by moisture meters were compared against the laboratory obtained data. Data was averaged and plotted with moisture content of various specimens and visually analysed to determine which meters deviated from the laboratory data and at which moisture contents. Data was also numerically analysed and graphed to quantify meter moisture content accuracy as compared to laboratory obtained moisture content.

Moisture meters should be used within the manufacturer specified range of moisture content and price may not be the best indicator of moisture meter accuracy. At low ranges of moisture content in wood and gypsum, all meters exhibited relatively small deviation from laboratory calculated values, while moderate and saturated conditions presented larger variations from laboratory moisture content. Composite materials such as gypsum may be difficult to establish moisture content, as different materials such as the gypsum core and paper facing absorb and distribute moisture differently. All meters were successful in detecting wet conditions, but exhibited a lack of precision in determining exact values in moderate and saturated conditions. In this regard, meters may be improved as the industry demands not only detecting wet conditions but determining precise values at a full range of moisture contents. Future studies may be limited to monolithic materials as oven dry method returns an average value of the respective paper and gypsum components in gypsum board specimens, and thus contained an inherent margin of error.
\end{abstract}

Keywords: Forensic Engineering ; Building Science; Material Science; Moisture Meter; Water Exposure; Building Materials; Duration of Loss; Wood; Gypsum Board; Drywall; Sheetrock; Roof Leak; Plumbing Leak; Insurance Claim.

\section{Introduction}

Various types of leaks may expose the built environment to a range of potential moisture contents. A common roof or window leak causes low-volume moisture intrusion that subjects the interior building components to an intermittent

\footnotetext{
* Corresponding author: abelcrean@outlook.com
}

DOI: http://dx.doi.org/10.21859/cej-03091

$>$ This is an open access article under the CC-BY license (https://creativecommons.org/licenses/by/4.0/).

(C) Authors retain all copyrights. 
source and corresponding elevated moisture content, while a sudden plumbing leak may result in near saturated conditions [1-5]. Extended moisture exposure to wood and gypsum interior building components causes fungal growth, deterioration, and eventual weakening of the material [6]. The wide range of possible moisture contents within a building subjected to a leak prompts the question as to the precision of moisture meters at a range of contents, substrates, and which meter is more effective under which specific circumstance.

The built environment presents a range of substrates that may be encountered. Wood is a common building material in the northern states, while regional construction trends in the southern United States result in substantial amounts of structures built with reinforced concrete, concrete block, and applied stucco, albeit still containing wood components. Gypsum wallboard and cementitious plaster were previously utilized for interior finishes in the early and mid 19th century and are still commonly found in many older buildings. Due to manufacturing improvements, modern gypsum board (drywall) has become commonplace, almost ever-present, since the 1970's [7].

A wide variety of price and style of moisture meters are available on the market today. Some meters are surface scanning while others incorporate pins to physically probe the material. A few meters offer combined scanning and pin functions in one tool. Some specialty meters are available for use in wood or concrete, and measurements taken from a specific substrate may be converted to another substrate by way of applying manufacturer provided conversion tables [8]. The overall manufacturing trend is to provide one meter that functions in a variety of building materials. Generally, moisture meter prices range from $\$ 30$ USD to around $\$ 250$ USD in retail stores to meters that command up to $\$ 600$ from specialty manufacturers.

Moisture content (MC) is most often calculated by weight as in Equation 1. As materials in the built environment cannot easily be removed and weighed, moisture meters utilize material properties to calculate MC while leaving the component in place. Non-penetrating moisture meters function by radio frequencies and may be falsely triggered to display elevated moisture content by the presence of fasteners or other metal components. Pin-type moisture meters function by measuring electrical resistivity [9]. As water is an excellent conductor, electrical resistivity decreases with increasing water content [10]. Proprietary formulas account for variations in temperature, and display MC as a percentage [11]. In this study, only pin-style meters were utilized as they offered a direct method of measurement and numerical quantification, while scanning meters were not used as they may only generally indicate low, medium, or high moisture content.

$$
M C=\frac{\text { Weight of water }}{\text { Weight of material }}
$$

\section{Experimental Setup and Methodology}

The intent of this study was to test meter accuracy at a range of moisture contents that may be encountered in the built environment. As accuracy of moisture content obtained from meter readings was the primary consideration, a narrow range of substrates was selected. Gypsum board drywall and wood building products are near universal in modern construction. In fact, it would be difficult to find a contemporary structure that does not incorporate both of these materials in some fashion.

SheetRock brand 15.875 millimeter $(\mathrm{mm})$ gypsum panel material specifications

$\begin{array}{ll}\text { Density } & 10.7 \text { kilograms }(\mathrm{kg}) \text { per square meter }\left(\mathrm{m}^{2}\right) \\ \text { Humidified deflection } & \text { less than } 15.875 \mathrm{~mm} \\ \text { Conductance } & 8.8 \text { Watt }(\mathrm{w}) \text { per meter }(\mathrm{m}) \text { by degree Kelvin }(\mathrm{K})\end{array}$

Common white pine wood material specifications

Density $\quad 0.373$ grams (g) per cubic centimeter (cc)

Modulus of Elasticity $\quad 868 \mathrm{~kg}$ per square $\mathrm{mm}$

Conductance $\quad 0.04-0.12 \mathrm{w}$ per $\mathrm{m}$ by $\mathrm{K}$

Wood and gypsum were purchased from a big-box retail hardware/ lumber supply store to simulate common building materials encountered in the built environment. Nine wood specimens consisted of approximately $139.7 \times 139.7 \times 19.05$ millimeter (mm) section of common white pine board as per Figure 1. Wood specimens were cut from the same board in lengths which equaled the standard board width, to form a square specimen. Minor wood knots and wood grain variations were present and were randomly distributed as they naturally occurred. 


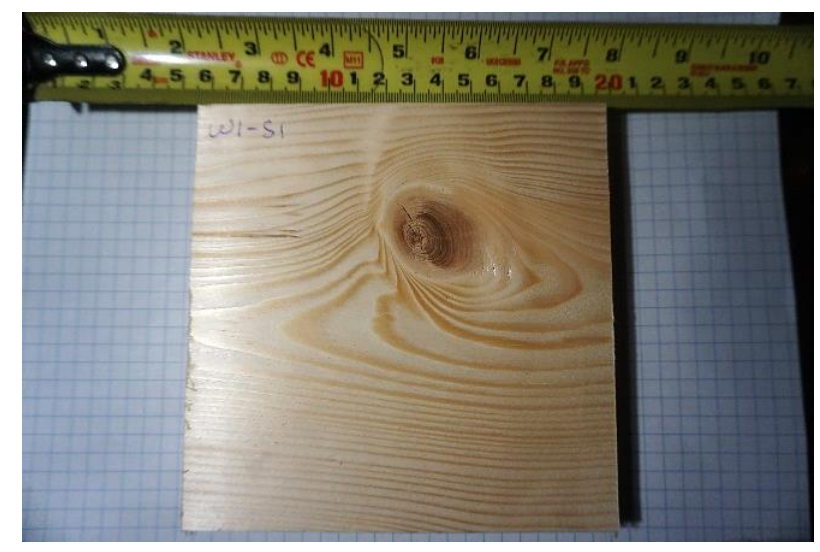

Figure 1. Wood specimen W1-S1 with knot and grain pattern variations

Nine gypsum (common drywall) specimens were a $139.7 \times 139.7 \times 15.875$ thick piece of common 1 -hour fire-rated gypsum board as per Figure 2. Gypsum board specimens were cut to the same size as the wood specimens to provide a consistent surface area and volume throughout all specimens. Surface area and volume did vary slightly as the standard width of wood and gypsum varied by $3.175 \mathrm{~mm}$. Factory side (butt) edges were left intact while tapered long (rip) edges were removed.

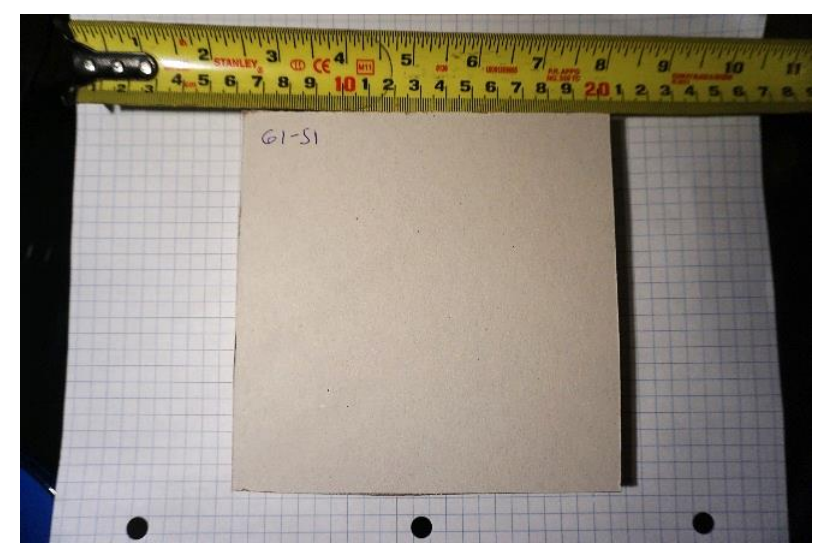

Figure 2. Gypsum specimen with factory and cut edges

Specimens were labeled $\mathrm{W}$ and $\mathrm{G}$, for wood and gypsum respectively. A subsequent numerical designation corresponded to the sample set. For example, W0 was the wood control, while G1 corresponded to gypsum set 1 . The post designation S1, S2, or S3 referred to the specimen number within the set. For example, W2-S3 equated wood, set 2 , and specimen 3 .

Table 1. Specimen sizes, material, and time exposed to water

\begin{tabular}{cccc}
\hline Specimen Name & Size $(\mathbf{m m})$ & Material & Time Exposed (hour) \\
\hline W0-S1 & $139.7 \times 139.7 \times 19.05$ & Common pine wood & 0 (control) \\
W0-S2 & $139.7 \times 139.7 \times 19.05$ & Common pine wood & 0 (control) \\
W0-S3 & $139.7 \times 139.7 \times 19.05$ & Common pine wood & 0 (control) \\
G0-S1 & $139.7 \times 139.7 \times 15.875$ & Gypsum board & 0 (control) \\
G0-S2 & $139.7 \times 139.7 \times 15.875$ & Gypsum board & 0 (control) \\
G0-S3 & $139.7 \times 139.7 \times 15.875$ & Gypsum board & 1 \\
W1-S1 & $139.7 \times 139.7 \times 19.05$ & Common pine wood & 1 \\
W1-S2 & $139.7 \times 139.7 \times 19.05$ & Common pine wood & 1 \\
W1-S3 & $139.7 \times 139.7 \times 19.05$ & Common pine wood & 1 \\
G1-S1 & $139.7 \times 139.7 \times 15.875$ & Gypsum board & 1 \\
G1-S2 & $139.7 \times 139.7 \times 15.875$ & Gypsum board & 33 \\
G1-S3 & $139.7 \times 139.7 \times 15.875$ & Gypsum board & 33 \\
W2-S1 & $139.7 \times 139.7 \times 19.05$ & Common pine wood & 33 \\
W2-S2 & $139.7 \times 139.7 \times 19.05$ & Common pine wood & 24 \\
W2-S3 & $139.7 \times 139.7 \times 19.05$ & Common pine wood & 24 \\
G2-S1 & $139.7 \times 139.7 \times 15.875$ & Gypsum board & 24 \\
G2-S2 & $139.7 \times 139.7 \times 15.875$ & Gypsum board & Gypsum board \\
G2-S3 & $139.7 \times 139.7 \times 15.875$ & & 1 \\
\hline
\end{tabular}


The control specimens consisted of three wood and three gypsum specimens which were not exposed to water, intending to simulate moisture conditions within a normal range. 3 liters of water was placed in a 37.8 liter clear, plastic container which measured 65.5 long $\times 40.1$ wide $\times 17.5$ high, in centimeters $(\mathrm{cm})$. Name brand spring water purchased at a grocery store was used to closely simulate rainwater. Wood and gypsum specimens from each set were placed floating as per Figure 3. Set 1 specimens were left in water for 1 hour, intending to replicate moderately wet conditions. Set 2 wood specimens were left for 33 hours, and gypsum specimens for 24 hours, to simulate near saturated conditions. Temperature and relative humidity were $25.39^{\circ} \mathrm{C}$ and $48 \%$, respectively.

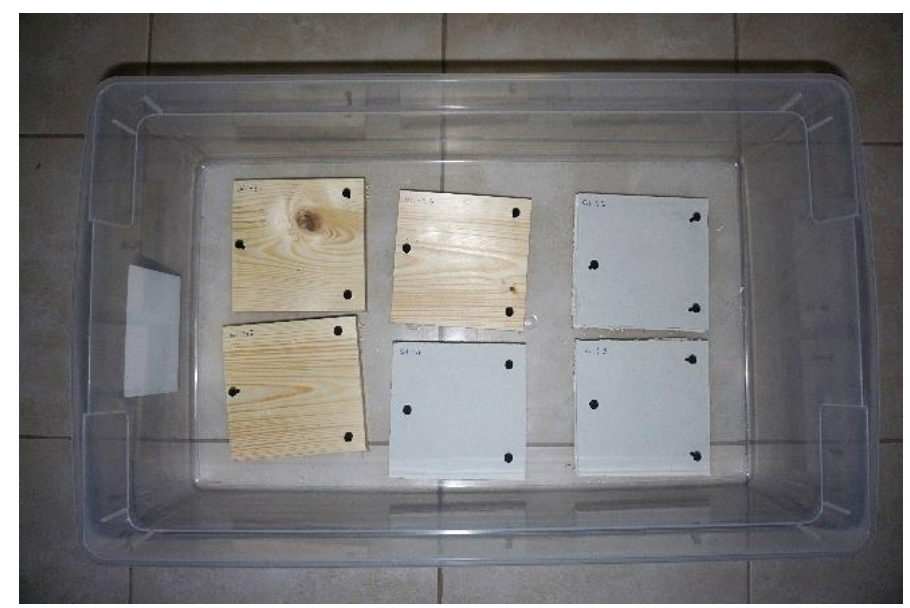

Figure 3. Set 1 specimens in plastic container

Uniform moisture content was ensured by the placement of a second container on top of the floating sample, submerging the specimens slightly as per Figure 4. Shims which consisted of metal drywall screws left protruding from the specimen formed a gap which ensured the top of the specimens were exposed to water on all sides while submerged as per Figures 5 and 6 .

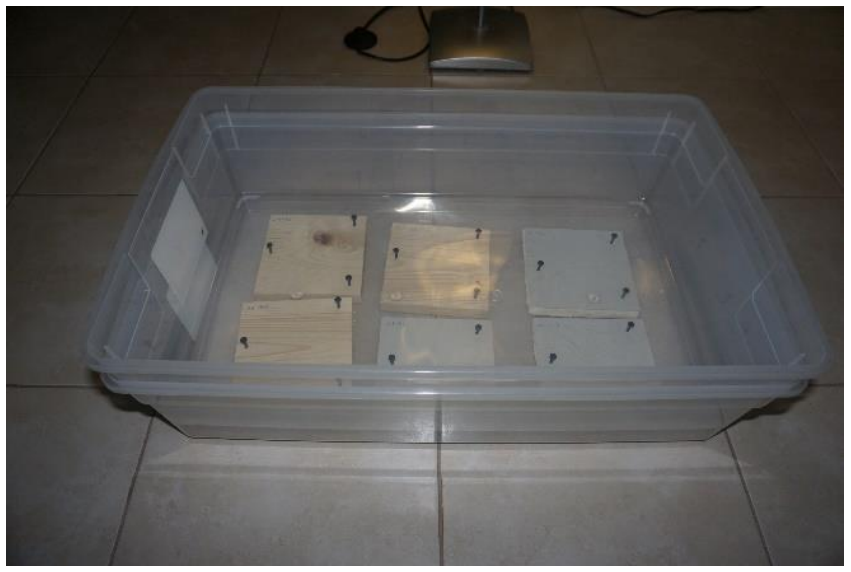

Figure 4. W1 and G1 specimens floating in plastic container covered by second container

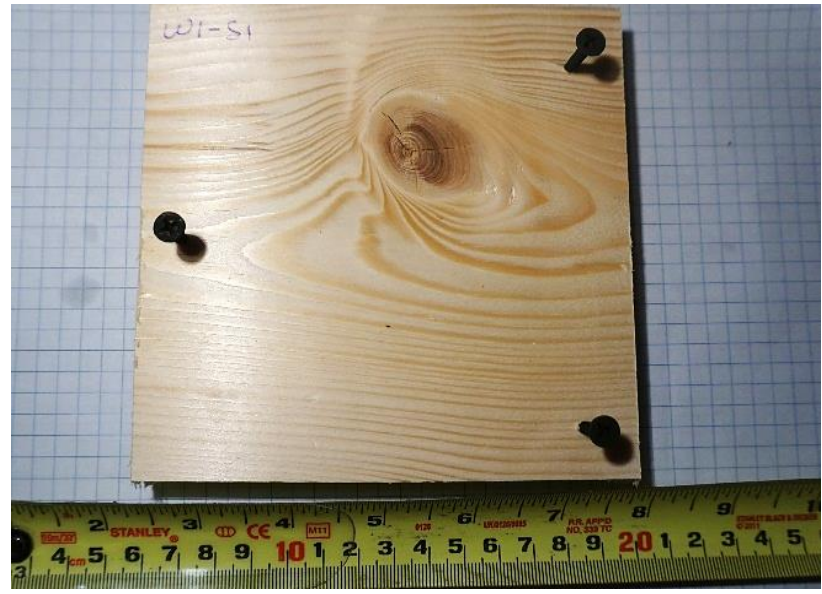

Figure 5. Specimen W1-S1 with shims 


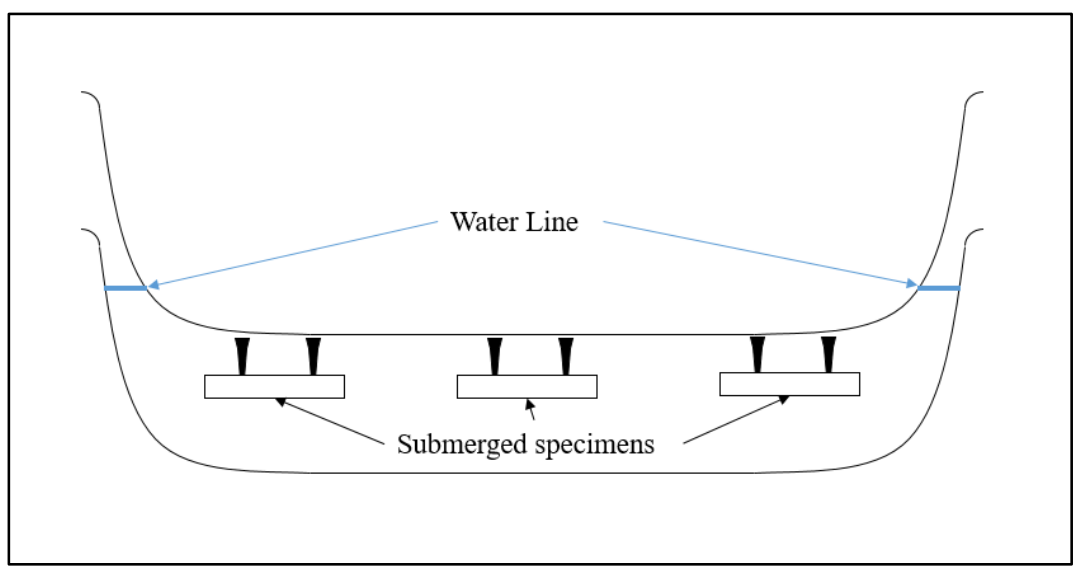

Figure 6. Experimental setup section view

Moisture meters were purchased new from online and retail stores, intending to simulate the range of inexpensive, mid-range, and pricy models on the market. Blind testing was not possible due to the nature of the tool, pin probe, and display screen. Moisture meter brands were not stated to maintain brand anonymity and to avoid potential liability. As meters were purchased new, meters were assumed to be adequately factory calibrated and were not altered or calibrated in any way as a part of this experiment. After the specified periods of wetting, four different brands of moisture meter were utilized to determine the moisture content of specimens by manual pin type measurements. The data were recorded and input into a spreadsheet for further analysis.

- Meter E had a retail price of \$320 United States Dollars (USD) and was a dual function scanning and pin type meter, with $9 \mathrm{~mm}$ long pins. The pin setting had a moisture range of $6 \%$ to $94.8 \%$ according to the manufacturer instruction manual and the instruction manual specified a $\pm 5 \%$ accuracy range.

- Meter G had a retail price of \$35 USD and was a sole pin style meter with $22 \mathrm{~mm}$ long pins. The meter had separate settings for wood and gypsum, which were used in the corresponding materials during the study. According to the manufacturer instruction manual, the meter had a range of 5\% to 50\% for wood substrates and $1.5 \%$ to $33 \%$ for building materials and did not have a manufacturer specified accuracy range in the provided user's manual.

- Meter S had a retail price of \$599 USD and was a dual function scanning and pin type meter with $22 \mathrm{~mm}$ long pins. The pin setting had a moisture range of $7.9 \%$ to $99 \%$ according to the manufacturer instruction manual. Meter S did not have a manufacturer specified accuracy range in the provided user's manual.

- Meter T had a retail price of \$342 USD. Meter T was a sole pin style meter with $30 \mathrm{~mm}$ long pins, and separate settings for wood and gypsum, which were used in the corresponding materials during the study. The wood setting contained sub-settings for different species. The wood sub-setting pine-cypress-white was used during the study. The pin setting had a moisture range of $6 \%$ to $46 \%$, according to the manufacturer instruction manual and the instruction manual specified a $\pm 0.1 \%$ accuracy range.

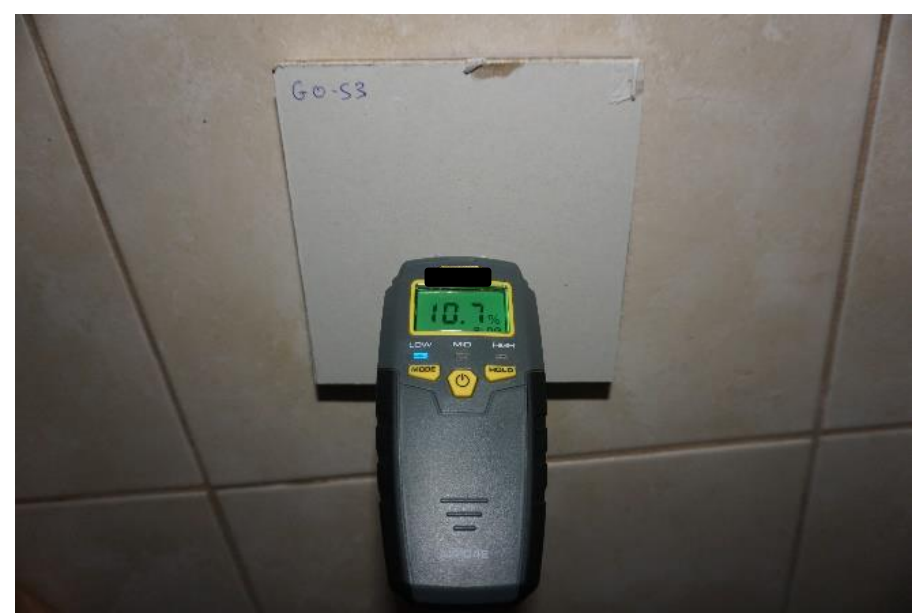

Figure 7. Meter G probing specimen G0-S3 
Shims were removed before testing MC. Control specimens did not have shims placed in them and were not exposed to any moisture. They were tested for MC and wrapped immediately. The central portion of all specimens were probed in with each meter within an approximately $30 \mathrm{~mm}$ square area. After moisture testing, specimens were sealed in plastic bags which were also labeled with the specimen designation. All specimens were sent together to an American Industrial Hygiene Association (AIHA) accredited laboratory which conformed to ISO/IEC17205:2005. The laboratory calculated the MC by the oven-dry method as noted in Equation 2 [12]. Specimens were oven-dried and weighed on the third and fourth day. The weights obtained from the fourth day were used to calculate the laboratory obtained MC. An adjustment of Equation 2. was utilized to account for a potential source of error. Moisture may evaporate from the specimens, condense on packaging material and escape from the bags as vapor. Consequently, the bags and specimens were weighed together before opening and the bags were air dried and subtracted from the final oven dry weight of the specimens, as noted in Equation 3. Measured moisture content was compared to the laboratory calculated values and the subsequent data trends were analyzed and plotted graphically.

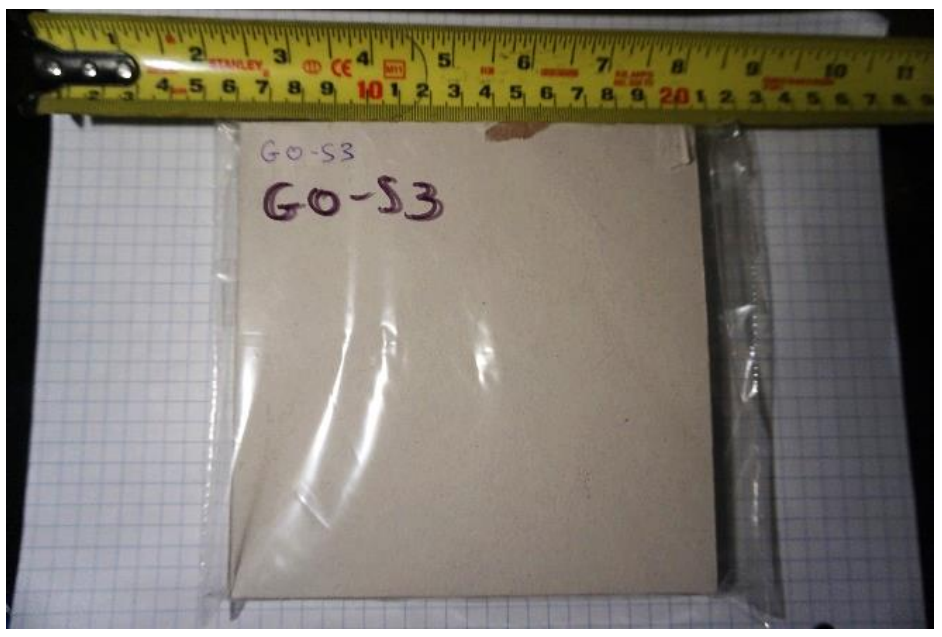

Figure 8. Gypsum control specimen 3 in plastic bag

$M C=\frac{\text { Initial weight-ovendryweight }}{\text { oven dryweight }} \times 100$

$M C=\frac{\text { Initial specimen weight (in bag)-oven dry specimen weight-bag weight(air dry) }}{\text { oven dry specimen weight }} \times 100$

\section{Data}

This section presents the data measured by moisture meters and laboratory obtained values for each sample set and specimen. Data will be presented here and elaborated upon in Section 4. Discussion. The average values were calculated of the three specimens within each sample set. Average deviation of all specimens within each set (ie: W0, W1, W2, G0, G1, or G2) from laboratory obtained moisture content was calculated to quantify meter accuracy as in Equation 3. The calculated deviation was displayed in the last column of data in Tables 2 and 3. For visual analysis, data was also plotted by moisture content and specimen average.

Deviation from lab $\mathrm{MC}=$ Set average probed $\mathrm{MC}-$ Set average laboratory calculated MC

\subsection{Wood Data}

Table 2. Wood moisture content $(\%)$

\begin{tabular}{ccccccc}
\hline Set & Sample & S1 & S2 & S3 & Average & Deviation \\
\hline W0 & E & 10.9 & 11.1 & 12.1 & 11.36667 & 2.216667 \\
& G & 13.1 & 13 & 13.8 & 13.3 & 0.283333 \\
& S & 11.1 & 12 & 12.5 & 11.86667 & 1.716667 \\
& T & 11.4 & 12.2 & 12.4 & 12 & 1.583333 \\
& Lab & 13.26 & 13.8 & 13.69 & 13.58333 & - \\
W1 & E & 23 & 21.3 & 22 & 22.1 & 2.75
\end{tabular}




\begin{tabular}{|c|c|c|c|c|c|c|}
\hline & G & 24.1 & 21.7 & 22.3 & 22.7 & 3.35 \\
\hline & S & 27.2 & 23.5 & 25.4 & 25.36667 & 6.016667 \\
\hline & $\mathrm{T}$ & 26 & 21.7 & 21.3 & 23 & 3.65 \\
\hline & Lab & 18.76 & 19.77 & 19.52 & 19.35 & - \\
\hline \multirow[t]{5}{*}{ W2 } & $\mathrm{E}$ & 35 & 44.2 & 75.4 & 51.53333 & 26.16333 \\
\hline & G & 36.1 & 35.9 & 37.3 & 36.43333 & 11.06333 \\
\hline & $S$ & 40.4 & 40.2 & 42.1 & 40.9 & 15.53 \\
\hline & $\mathrm{T}$ & 28.6 & 27.8 & 21.1 & 25.83333 & 0.463333 \\
\hline & $\mathrm{Lab}$ & 33.56 & 32.2 & 10.35 & 25.37 & - \\
\hline
\end{tabular}

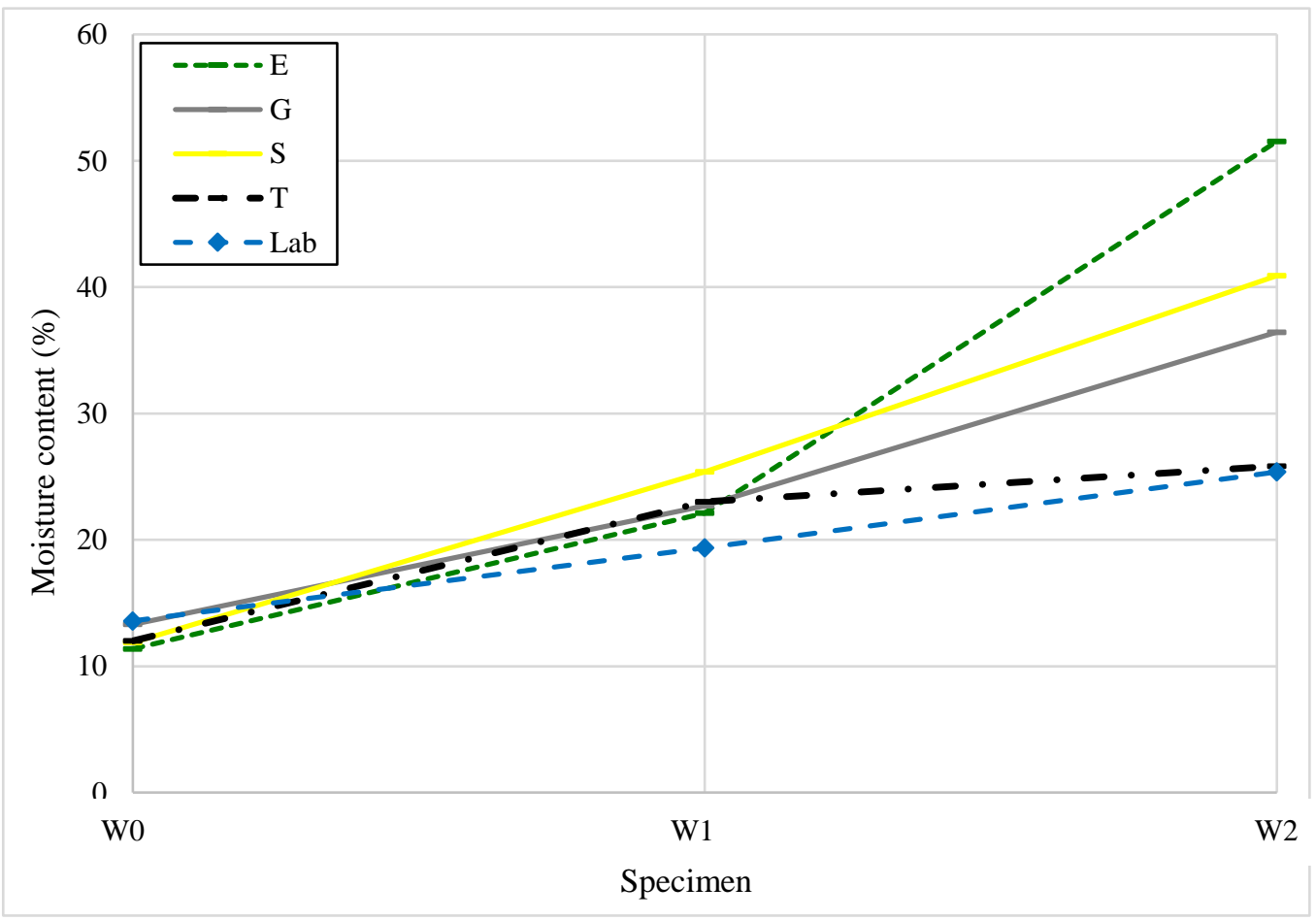

Figure 9. Average wood moisture content by sample set

\subsection{Gypsum Data}

Table 3. Gypsum moisture content (\%)

\begin{tabular}{ccccccc}
\hline Set & Sample & S1 & S2 & S3 & Average & Deviation \\
\hline \multirow{2}{*}{ G0 } & E & 12.7 & 11.8 & 11.7 & 12.06667 & 0.893333 \\
& G & 12 & 11.6 & 11.5 & 11.7 & 0.526667 \\
& S & 13.6 & 12.8 & 12.2 & 12.86667 & 1.693333 \\
& T & 0.4 & 0.3 & 0.4 & 0.366667 & 10.80667 \\
& Lab & 10.35 & 11.69 & 11.48 & 11.17333 & - \\
& E & 94.8 & 94.8 & 94.8 & 94.8 & 41.34333 \\
& G & 100 & 100 & 100 & 100 & 46.54333 \\
& S & 99.9 & 99.9 & 99.9 & 99.9 & 46.44333 \\
& T & 8.5 & 0.3 & 8.5 & 5.766667 & 47.69 \\
& Lab & 54.15 & 52.82 & 53.4 & 53.45667 & -
\end{tabular}




\begin{tabular}{|c|c|c|c|c|c|c|}
\hline \multirow[t]{5}{*}{ G2 } & E & 94.6 & 94 & 94.8 & 94.46667 & 29.40667 \\
\hline & G & 100 & 100 & 100 & 100 & 34.94 \\
\hline & S & 99.9 & 99.9 & 99.9 & 99.9 & 34.84 \\
\hline & $\mathrm{T}$ & 8.5 & 8.5 & 8.5 & 8.5 & 56.56 \\
\hline & Lab & 62.47 & 62.62 & 70.09 & 65.06 & - \\
\hline
\end{tabular}

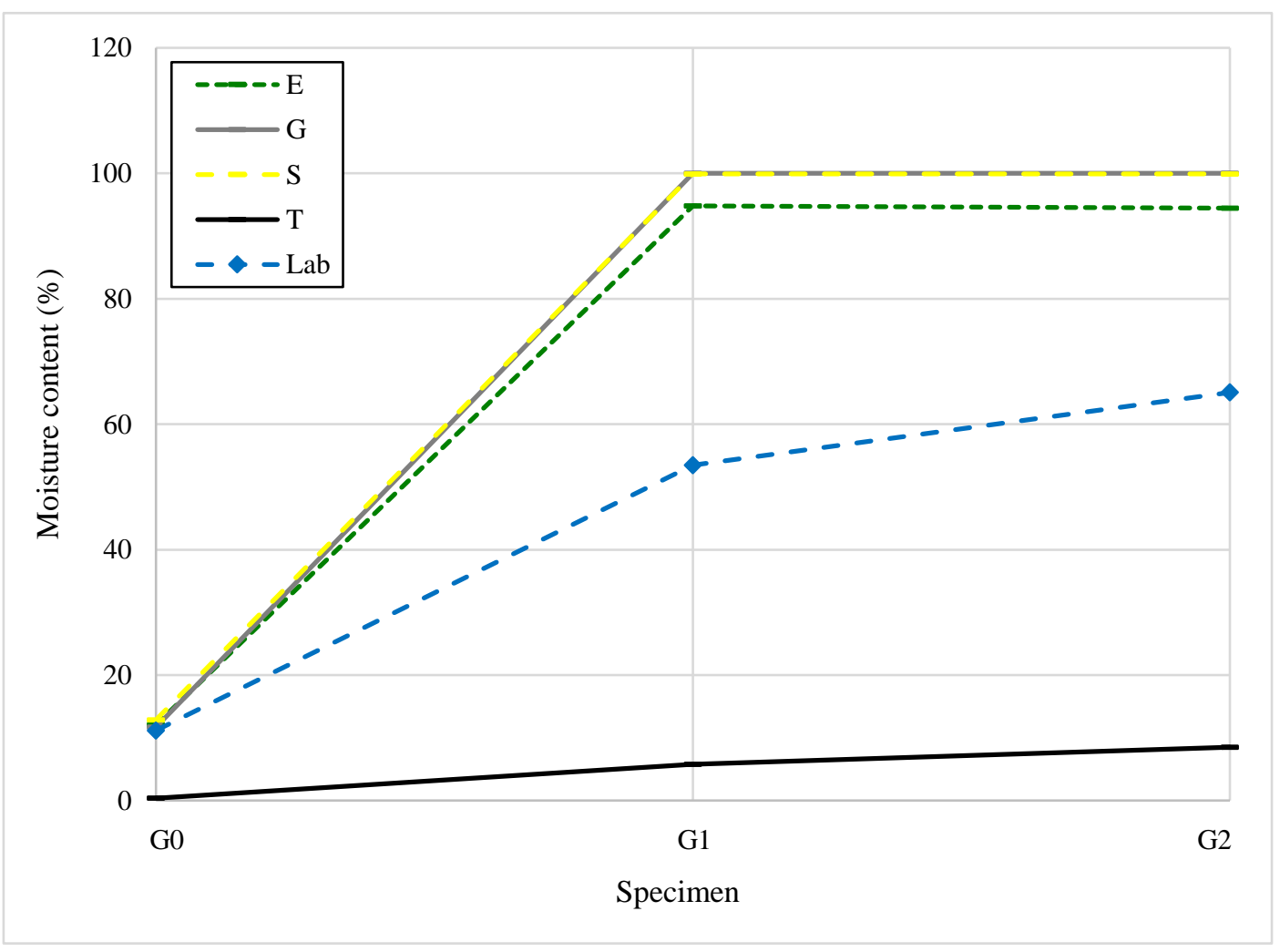

Figure 10. Average gypsum moisture content by sample set

\section{Discussion}

\subsection{Wood}

\subsubsection{Wo (Control)}

From visual observation of Figure 9, it was apparent that moisture content measured by all meters did not greatly vary from laboratory calculated values in low MC (normal) conditions. At low moisture content, the largest deviation was Meter $\mathrm{E}$ at $2.21 \%$. Meter $\mathrm{G}$ had the lowest deviation of $0.28 \%$ which indicated that all meters were very accurate at low moisture contents in wood substrates.

\subsubsection{W1}

In moderately wet conditions, the maximum deviation was Meter $\mathrm{S}$ at $6.01 \%$. Meter $\mathrm{E}$ had the lowest deviation of $2.75 \%$ which indicated that all meters were relatively accurate in moderately wet conditions, and fell within a small margin of error.

\subsubsection{W2}

In near saturated conditions, Meter E exhibited the largest deviation at $26.16 \%$. Meter T had the lowest deviation of $0.46 \%$ and was, by far, the most accurate meter in determining precise moisture content in near saturated conditions. One possible explanation was that Meter T proprietary formulas allowed for slight variations in MC within the wood substrate due to grain characteristics, while Meters E, G, and S were triggered solely by the presence of localized high moisture content and returned corresponding high values. Meter G and Meter S exhibited deviations of 11.06 and 15.53 $\%$ respectively, which may be considered acceptable margins of error depending on the application. 


\subsection{Gypsum}

\subsubsection{G0 (Control)}

From visual observation of Figure 10, it was apparent that moisture content measured by all meters did not greatly vary from laboratory calculated values in low MC (normal) conditions. At low MC, Meter T had the greatest deviation at $10.8 \%$. The lowest deviation was Meter $\mathrm{G}$ with $0.89 \%$. Meters $\mathrm{G}$ and $\mathrm{S}$ also exhibited low deviations at $0.52 \%$ and $1.69 \%$, respectively. This data indicated that Meter E, G, and S were very accurate at low moisture contents and Meter $\mathrm{T}$ functioned within a margin of error.

\subsubsection{G1}

In moderately wet conditions, Meter T had a deviation of $47.69 \%$ lower than the laboratory obtained MC. Meter T may have experienced an error as two of the sample measurements were exactly the same at $8.5 \%$. Meter E had the lowest variation at $41.34 \%$ higher than laboratory obtained MC. This data indicated that a high margin of error was present in wet conditions in gypsum board specimens and Meter T did not indicate wet conditions at all. One possibility for the aberrant data is that gypsum board is a composite material composed of compressed gypsum sandwiched between two outer paper layers. As material densities and characteristics vary, the MC may not have been uniform throughout the gypsum and paper drywall components. Laboratory calculated MC is returned as one number as if the MC were perfectly uniform, which may not have been the case. Meters E, G, and S, which all measured higher than the laboratory value, may have been triggered by wet conditions in the outer paper layer and returned corresponding high moisture content.

\subsubsection{G2}

Again Meter T measured lower than laboratory obtained MC, with the largest deviation at $56.56 \%$. Meter T may have exhibited an error as all 3 specimen values were 8.5, which is not considered wet. All other meters measured higher than the laboratory MC. Meter E had the lowest deviation of 29.4\% All moisture meters exhibited inaccurate moisture content as compared to laboratory obtained MC, but Meters E, G, and S were satisfactory in detecting wet conditions.

\section{Conclusion}

\subsection{General}

- Moisture meters should be used within their manufacturer specified range of moisture content. Values obtained outside of this range may not be accurate.

- Different brand meters are designed to be accurate within varying ranges of moisture content. For some practical purposes, once a material exhibits over $20 \% \mathrm{MC}$, it is wet; the precise moisture content may be irrelevant. The most important factor in the field is to accurately determine when a substrate is wet. How wet is it may retain little importance.

\subsection{Wood}

- All meters functioned well at low moisture content, within a very narrow margin of error.

- All meters functioned well in moderately wet conditions, within a two to six percent margin of error.

- Overall, by visual observation of Figure 9, Meter T was the most accurate meter over the range of moisture contents, and closely followed the general trend of laboratory obtained MC. Meter T also had the lowest total deviance from laboratory MC. As Meter T had the longest pins, pin length may have enabled more accurate measurements.

- In low moisture content, Meter G functioned precisely; at a $0.28 \%$ deviation from laboratory obtained MC.

- Meters $\mathrm{G}$ and $\mathrm{S}$ exhibited a reasonable margin of error at high moisture content

- Meter E was not accurate at high moisture content.

\subsection{Gypsum}

- All meters functioned well at low moisture content, within a very narrow margin of error.

- Due to variations in material characteristics, meters exhibit some level of inherent inaccuracy in composite materials such as modern gypsum board (drywall). Consequently, meters may overestimate the precise MC in moderately wet and saturated conditions by measuring wetness in outer paper facing. Meters were effective in detecting wet conditions, but failed to precisely quantify how wet.

- In moderately wet and saturated conditions, Meter T may have undergone a random error as it failed to detect wet conditions and five of the six measurements were the same numerical value. Such error represents the need to verify 
calibration of the meter after purchase and on a regular basis during use. Currently, Meter S is the only meter that comes stock with an electrode to verify accurate calibration.

- Ironically, Meter G (least expensive) and Meter S (most expensive) followed the same exact trend, returning 100\% wet values in moderately wet and saturated conditions, which may not have been technically correct moisture contents, but were both satisfactory in detecting wet conditions. It is also apparent from this data that price may not be the best indicator of measurement accuracy.

\section{Future Applications}

Evaluating moisture content in cementitious and epoxy building materials during curing may offer an inherent benefit by providing a method of analyzing the curing process that could potentially be applied to inhibit the development of shrinkage cracks [12]. Cementitious building materials designed with low water contents have precise, sensitive water/ cement $(\mathrm{w} / \mathrm{c})$ ratios which must be maintained at a low moisture content for maximum strength to develop. Water evaporates during mixing and transit, so measured water added to the mix does not equate actual water content. Evaluating moisture content of these cementitious materials before placement may provide a cost-effective method to analyze and adjust the mixture's water content or w/c ratio [13].

\section{Acknowledgements}

Chin Yang, PhD at Prestige EnviroMicrobiology in Voorhees, NJ for providing laboratory analysis services. Joseph Chaiban, PE, SI of Chaiban Engineering Consultants in Ft. Lauderdale, Florida for experiment methodology and content review. Ehssan Amir Sayyafi, PhD, EI at Florida International University in Miami, Florida for peer review.

\section{References}

[1] Bitsuamlak, Girma T., Arindam Gan Chowdhury, and Dhawal Sambare. "Application of a full-scale testing facility for assessing wind-driven-rain intrusion." Building and Environment 44, no. 12 (2009): 2430-2441.

[2] Baheru, Thomas, Arindam Gan Chowdhury, Girma Bitsuamlak, and Ali Tokay. "A parametric representation of wind-driven rain in experimental setups." In Advances in Hurricane Engineering: Learning from Our Past, pp. 270-282. 2013.

[3] Baheru, Thomas, Arindam Gan Chowdhury, Girma Bitsuamlak, Forrest J. Masters, and Ali Tokay. "Simulation of wind-driven rain associated with tropical storms and hurricanes using the 12-fan Wall of Wind." Building and Environment 76 (2014): 18-29.

[4] Amir-sayyafi, Ehssan, A. G. Chowdhury, and A. Mirmiran. "A supper Lightweight Hurrican-Resistant Thin-Walled Box-cell Roofing System." In International Symposium on Structural Engineering. (2016): 698-704.

[5] Sayyafi, E. A., Gan Chowdhury, A., \& Mirmiran, A. An Innovative Hurricane-Resistant UHPC Roof System. Journal of Architectural Engineering, (2017). In Press.

[6] 561 BUILD (2017). Retrieved from https://sites.google.com/view/561build/home/wood-decay-termite

[7] Gypsum Association. "Gypsum through the ages.” (2012) Web. Retrieved from https://www.gypsum.org/about/gypsum101/history-gypsum/

[8] Delmhorst Instrument Co. “J-4 Owner's Manual”. Jan (2006) Web. Retrieved from http://www.homedepot.com/catalog/pdfImages/8a/8a4666d4-0dba-4c63-ab30-c7ffe94eb9c8.pdf

[9] Delmhorst Instrument Co. "Building Inspection FAQs" July (2017) Web. Retrieved from http://www.delmhorst.com/FAQs/Building-Inspection

[10] Rhoades, J.D. Raats, P.A.C. Prather, R.J. "Effects of liquid phase electrical conductivity, water content, and surface conductivity on bulk soil electrical conductivity." Alliance of Crop, Soil, and Environmental Science Societies 40 (2013): 651-655

[11] Kitzio, F. Campbell, C.S. Campbell, G.S. Cobos, D.R. Teare, B.L. Carter, B. Hopmans, J. W. "Frequency, electrical conductivity and temperature analysis of a low-cost capacitance soil moisture sensor. Journal of Hydrology 352 (2008): 367-378.

[12] Reeb, Jim. Milota, Mike. "Moisture content by the oven dry method.” Oregon State University. (2012): 1

[13] Ahmad, I., N. Suksawang, K. Sobhan, J. Corven, E. A. Sayyafi, S. Pant, and F. Martinez. "Develop Epoxy Grout Pourback Guidance and Test Methods to Eliminate Thermal." Shrinkage Cracking at Post-Tensioning Anchorages: Phase II (2015).

[14] Ghasemi, Sahar, Pedram Zohrevand, Amir Mirmiran, Yulin Xiao, and Kevin Mackie. "A super lightweight UHPC-HSS deck panel for movable bridges." Engineering Structures 113 (2016): 186-193. 